\title{
Validitas Modul Pembelajaran Berbasis Guided Inquiry pada Materi Fluida di STKIP PGRI Sumatera Barat
}

\author{
Silvi Trisna ${ }^{\text {a) }}$, Aidhia Rahmi ${ }^{\text {b) }}$ \\ Pendidikan Fisika, STKIP PGRI Sumatera Barat, Jl. Gajah Mada No 1A, Padang, Sumatera Barat \\ Email: a)vina_sanguine@yahoo.com, b)aidhiarahmi@yahoo.co.id
}

\begin{abstract}
Fundamental physics is one subjects for Physics Education's Department in STKIP PGRI West Sumatra. For supporting the course and geting a good result it require the lecturer's note like module. The developed a lecturer's note is a module based guided inquiry that is expected to make students more active, creative and critical thinking as well as skilled in the discovery of the facts in Physics. Guided inquiry is a learning model which there are some activities that are scientific, students submit ideas before the topic studied, then investigate a phenomenon or phenomena. After that, the student explained that based on existing facts and compare them scientifically. This type of research is research and development using a Plomp's model is passing through the stages: (1) the initial investigation (preliminary research), (2) design and realization (prototyping phase), and (3) testing and assessment (assessment phase). On the preliminary research, curriculum analysis will be doing, so students analysis, and analysis of the concept. On prototyping phase the module for the Physics at the fluid is designed. Next, we get the formative evaluation that includes self evaluation, prototyping (expert reviews, one-toone and small group). We get the validity at this stage. The research data was obtained through the validation module sheet, which then produces a valid module.
\end{abstract}

Keywords: validity, modules, guided inquiry, fundamental physics, fluid

\begin{abstract}
Abstrak
Fisika Dasar merupakan salah satu mata kuliah Program Studi PendidikanFisika di STKIP PGRI Sumatera Barat. Untuk mendukung perkuliahan dan mendapatkan hasil belajar yang bagus maka dibutuhkan bahan ajar berupa modul. Bahan ajar yang dikembangkan merupakan modul yang berbasis guided inquiry yang diharapkan mampu membuat mahasiswa lebih aktif, kreatif, dan berfikir secara kritis serta terampil dalam penemuan fakta-fakta dalam Fisika Dasar. Guided inquiry adalah model pembelajaran yang didalamnya terdapat beberapa kegiatan yang bersifat ilmiah, mahasiswa menyampaikan ide-ide sebelum topik tersebut dipelajari, kemudian menyelidiki sebuah gejala atau fenomena. Setelah itu, mahasiswa menjelaskan berdasarkan fakta-fakta yang ada dan membandingkannya secara saintifik. Jenis penelitian yang digunakan adalah penelitian pengembangan (research and development) menggunakan model Plomp yaitu yang melewati tahapan: (1) investigasi awal (preliminary research), (2) perancangan dan realisasi (prototyping phase), dan (3) ujicoba dan penilaian (assessment phase). Pada tahap preliminary research dilakukan analisis kurikulum, analisis mahasiswa, dan analisis konsep. Pada tahap prototyping phase dilakukan perancangan modul untuk mata kuliah Fisika Dasar pada materi fluida. Setelah itu dilakukan langkah formative evaluation yang meliputi self evaluation, prototyping (expert reviews, one-to-one, dan small
\end{abstract}


group). Pada tahap ini dilakukan validitas. Data penelitian ini diperoleh melalui lembar validasi modul, yang kemudian menghasilkan modul yang valid.

Kata-kata kunci: validitas, modul, guided inquiry, fisika dasar, fluida

\section{PENDAHULUAN}

Pendidikan merupakan bagian dari kebudayaan dalam proses kehidupan manusia. Di satu pihak, pendidikan merupakan salah satu cara atau wahana untuk meneruskan nilai-nilai budaya dari generasi terdahulu kepada generasi berikutnya. Dipihak lain, kebudayaan merupakan wujud semangat kehidupan manusia yang menjiwai proses pendidikan dalam dinamika kehidupan masyarakat. Berbagai usaha telah dilakukan oleh berbagai pihak atau kalangan, baik pemerintah maupun swasta dalam rangka peningkatan pendidikan, baik jumlah (kuantitas) maupun kualitasnya (mutunya).

Salah satu tujuan dari pendidikan nasional adalah usaha untuk mencerdaskan kehidupan bangsa. Tanpa pendidikan yang baik, bangsa Indonesia sulit meraih masa depan yang cerah, damai dan sejahtera (Mulyasa 2008). Fisika merupakan salah satu mata pelajaran yang dikaitkan dengan kecerdasan bangsa yang memiliki peranan besar dalam menunjang ilmu pengetahuan dan teknologi, sehingga menggugah para pendidik untuk dapat merancang dan melaksanakan pendidikan yang lebih terarah pada penguasaan konsep fisika yang dapat menunjang dalam kehidupan sehari-hari.

Fisika sebagai bagian dari Sains mempunyai peranan yang penting dalam meningkatkan kualitas sumber daya manusia terutama dalam menunjang perkembangan ilmu pengetahuan alam dan teknologi. Hal ini dapat dilihat dari penerapan ilmu fisika dalam disiplin ilmu lainnya dan aplikasinya pada perkembangan teknologi. Sehingga mata pelajaran fisika perlu diperkenalkan sejak dini mulai dari Sekolah Dasar, Sekolah Menengah, hingga ke Perguruan Tinggi. Di perguruan tinggi ilmu Fisika dikaji lebih mendalam, sehingga mampu melahirkan para pemikir muda yang berintelektual tinggi. Hal ini dapat tercapai dengan mudah jika proses belajar dan pembelajaran berjalan dengan semestinya. Mengingat begitu berperannya ilmu fisika bagi manusia, sehingga kualitas pembelajaran fisika harus ditingkatkan.

Salah satu mata kuliah Program Studi Pendidikan Fisika adalah Fisika Dasar dengan bobot 4 sks. Mata kuliah ini merupakan tonggak dari kajian Fisika yang sangat dibutuhkan dalam mempelajari ilmu fisika tingkat lanjut. Oleh sebab itu, penguasaan Fisika Dasar harus dipahami dengan baik dan pelaksanaan pembelajaran di kelas, dosen dapat melakukan pembelajaran yang mampu mengembangkan kemampuan berfikir mahasiswa.

Kondisi yang terjadi di lapangan nampaknya cukup berat bagi mahasiswa. Pada semester satu mahasiswa masih dalam proses penyesuaian diri dengan sistem pembelajaran di perguruan tinggi, sedangkan mata kuliah Fisika Dasar mengharuskan mahasiswa bekerja keras dalam menguasai konsep yang diberikan. Pengetahuan yang diperoleh mahasiswa dalam pembelajaran Fisika Dasar di kelas masih terbatas, untuk itu dosen perlu meningkatkan pengetahuan ini dengan penalaran mahasiswa melalui penemuan sendiri hal-hal baru dalam bentuk pengalaman belajar. Hal ini penting, mengingat Fisika Dasar merupakan dasar dari semua mata kuliah yang akan dipelajari pada semester selanjutnya.

Berdasarkan pengamatan, proses pembelajaran yang terjadi belum sepenuhnya melibatkan mahasiswa secara optimal. Pembelajaran yang berkualitas ditunjukkan oleh tingkat interaksi dan partisipasi aktif mahasiswa dalam proses pembelajaran. Hal ini dapat dilakukan dengan penerapan model pembelajaran inovatif yang mampu mengatasi permasalahan rendahnya pemahaman konsep dan penerapan konsep, dan kinerja ilmiah mahasiswa, salah satunya pembelajaran inkuiri.

Pembelajaran inkuiri berarti suatu rangkaian kegiatan yang melibatkan secara maksimal seluruh kemampuan mahasiswa untuk mencari dan menyelidiki secara sistematis, kritis, logis, analogis sehingga mereka dapat merumuskan sendiri penemuannya. Inkuiri merupakan suatu proses yang bermula dari merumuskan masalah, merumuskan hipotesis, mengumpulkan data, dan membuat kesimpulan. Pembelajaran inkuiri dirancang untuk mengajak mahasiswa langsung ke dalam proses ilmiah dalam waktu yang relatif singkat. Strategi yang secara aktif melibatkan siswa dalam proses 
pembelajaran melalui penyelidikan ilmiah lebih mungkin meningkatkan pemahaman konseptual dari strategi yang mengandalkan teknik yang lebih pasif, yang sering diperlukan dalam standar penilaian lingkungan pendidikan yang sarat saat ini (Minner, dkk 2010).

Sasaran utama pembelajaran inkuiri adalah (1) keterlibatan mahasiswa secara maksimal dalam proses pembelajaran, (2) keterarahan kegiatan secara logis dan sistematis pada tujuan pembelajaran, (3) mengembangkan sikap percaya diri tentang apa yang ditemukan dalam proses inkuiri. Inti dari inkuiri adalah pengetahuan yang diperoleh mahasiswa bukan hanya mengingat fakta dan teori tapi merujuk pada kegiatan pembelajaran yang bersifat menemukan sendiri dengan arahan dosen.

Untuk meningkatkan penguasaan konsep dan kesempatan kepada mahasiswa untuk bekerja merumuskan prosedur, menganalisis hasil dan mengambil kesimpulan secara mandiri, maka dosen merancang sebuah pembelajaran menggunakan model pembelajaran guided inquiry. Hal ini dilakukan agar mahasiswa lebih memahami mata kuliah Fisika Dasar serta memaksimalkan potensi yang dimiliki sehingga tujuan dari pembelajaran dapat tercapai. Jika mahasiswa telah menguasai konsep dari Fisika Dasar dengan baik maka akan mempermudah mereka dalam memahami ilmu fisika lebih lanjut.

Pembelajaran berbasis guided inquiry ini dapat dikonversi dalam bentuk modul berbasis guided inquiry. Dengan menggunakan modul ini, mahasiswa diarahkan untuk belajar mandiri dalam pengetahuan baru dengan menggunakan pengetahuan yang sudah ada sebelumnya. Mahasiswa belajar secara mandiri tanpa mengharapkan seluruh materi ditransfer oleh dosen pengampu mata kuliah dan menemukan sendiri konsep yang ada dengan menggunakan modul guided inquiry yang akan dirancang.

Tujuan dari penelitian ini sendiri adalah bagaimana mengembangkan modul Berbasis Guided Inquiry pada materi fluida yang valid.

\section{METODE PENELITIAN}

Berdasarkan rumusan masalah yang telah dikemukakan maka jenis penelitian yang dilakukan adalah penelitian pengembangan (Research and Development). Dalam hal ini dikembangkan suatu modul pembelajaran dengan menggunakan model guided inquiry yang valid. Penelitian pengembangan yang dilakukan mengacu pada model pengembangan perangkat pembelajaran oleh Plomp (2010) yaitu yang melewati tahapan: (1) investigasi awal (preliminary research), (2) perancangan dan realisasi (prototyping phase), dan (3) uji coba dan penilaian (assessment phase).

Instrumen yang digunakan dalam penelitian adalah lembar validitas, dimana angket validitas disusun menurut skala Likert. Data penelitian dikumpulkan melalui validasi modul dengan menggunakan lembar validasi oleh pakar dan praktisi pendidikan yang sesuai dengan bidang kajiannya. Analisis validasi dilakukan dengan menggunakan skala likert dengan ketentuan: kurang baik $=1$, cukup baik $=2$, baik $=3$, dan sangat baik $=4$. Perhitungan nilai akhir hasil validasi dinyatakan dalam skala (0-100) dilakukan dengan menggunakan persamaan (Riduwan 2009):

$$
p=\frac{f}{n} \times 100 \%
$$

\section{HASIL DAN PEMBAHASAN}

Penelitian yang dilakukan adalah penelitian pengembangan (Research and Development). Dalam hal ini dikembangkan suatu modul pembelajaran Fisika Dasar dengan menggunakan model guided inquiry yang valid. Penelitian pengembangan yang dilakukan mengacu pada model pengembangan perangkat pembelajaran oleh Plomp.

Di awal pengembangan dilakukan fase investigasi awal (preliminary research). Pada tahap ini dilakukan analisis awal atau identifikasi masalah, analisis kebutuhan dan analisis konsep atau isi materi, dan pengkajian literatur yang diperlukan dalam pembelajaran.

Analisis isi materi pembelajaran bertujuan untuk menentukan isi dan materi perkuliahan yang dibutuhkan dalam pengembangan perangkat pembelajaran. Dalam analisis materi peneliti melakukan 
identifikasi terhadap konsep esensial dari materi pada perkuliahan fisika dasar yaitu fluida. Materi fluida dikembangkan menjadi sub materi fluida statis dan fluida dinamis.

Dilihat dari materi yang sudah diberikan sebelumnya belum mampu meningkatkan aktivitas mahasiswa selama perkuliahan. Hal ini disebabkan karena materi yang disajikan memperlihatkan konsep secara langsung. Mahasiswa masih mengalami kesulitan dalam memahami konsep sehingga berdampak pada masih rendahnya minat mahasiswa terhadap perkuliahan Fisika dasarpada materi Fluida. Materi yang diberikan belum sepenuhnya menyajikan masalah-masalah yang berkaitan sehingga mahasiswa cenderung menerima apa yang diberikan oleh dosen. Sehingga, capaian pembelajaran dari pembelajaran Fisika dasar pada materi fluida kurang tercapai.

Selain itu, peneliti juga melakukan kajian terhadap literatur yang tersedia. Berdasarkan hasil survei, di perpustakaaan telah tersedia buku-buku fisika dasar. Akan tetapi, penggunaan buku tersebut masih belum optimal. Kondisi ini disebabkan mahasiswa yang kurang berminat untuk menggunakan literatur yang tersedia. Oleh karena itu, perlu pengembangan modul sehingga diharapkan mahasiswa dapat lebih termotivasi untuk memanfaatkan literatur yang tersedia.

Selanjutnya berdasarkan hasil wawancara dengan dosen diketahui bahwa dosen mengalami kesulitan dalam memberikan materi perkuliahan kepada mahasiswa. Hal ini dikarenakan masih kurangnya minat baca mahasiswa terhadap literatur yang ada sehingga berdampak kepada kurangnya pemahaman mahasiswa terhadap materi yang diberikan. Bahan ajar yang sudah digunakan belum mampu menuntut keaktivan mahasiswa sepenuhnya sehingga mahasiswa masih bergantung kepada dosen.Sedangkan untuk metode pembelajaran yang sering diterapkan dosen di dalam kelas adalah dengan diskusi, dimana dalam prosesnya masih banyak mahasiswa yang tidak aktif selama kegiatan diskusi tersebut. Dilihat dari bahan ajar yang digunakan dosen lebih banyak memuat materi sedangkan untuk penyajian permasalahan yang harus diselesaikan oleh mahasiswa masih kurang. Dosen berpendapat bahwa penggunaan modul yang berbasis guided inquiry bisa membantu mahasiswa untuk lebih memahami konsep.

Sementara hasil wawancara terhadap mahasiswa diperoleh bahwa mahasiswa masih terkendala dalam memahami materi perkuliahan yang diberikan. Hal ini dikarenakan kurangnya minat baca mahasiswa terhadap literatur yang ada. Untuk kegiatan dalam perkuliahan juga belum mengeksplor kemampuan mahasiswa dalam menyelesaikan permasalahan yang berkaitan dengan materi yang diajarkan. Seterusnya pemahaman mahasiswa dalam mencerna bahasa yang digunakan dalam literatur masih rendah sehingga diperlukan bahan ajar yang menyajikan materi dengan lebih sederhana. Berikut bentuk format wawancara untuk dosen dan mahasiswa.

Setelah itu dilakukan fase perancangan dan realisasi (prototyping phase) dengan perumusan/ perancangan terhadap modul. Berdasarkan investigasi awal yang dilakukan terhadap dosen dan mahasiswa maka dilakukan perancangan modul berbasisguided inquiry. Modul yang dibuat adalah sebuah bahan ajar yang ditulis dengan tujuan agar mahasiswa dapat belajar secara mandiri tanpa atau dengan bimbingan dosen serta mampu menggali kemampuan mahasiswa dalam memahami materi yang diberikan sehingga meningkatkan pemahaman mahasiswa. Modul berisi petunjuk belajar, capaian pembelajaran, isi materi, informasi pendukung, tugas terstruktur yang dikaitkan dengan komponen atau tahapan padaguided inquiry yaituorientasi, merumuskan masalah, mengajukan hipotesis, mengumpulkan data, menguji hipotesis, dan merumuskan simpulan.

Pada tahap ini dilakukan formative evaluation yang meliputi self evaluation, prototyping (expert reviews, one-to-one, dan small group), serta field test. Adapun alur desain formative evaluation seperti ditunjukkan pada GAMBAR 1.

Penelitian ini dilakukan hanya sampai pada tahap expert reviews. Pada tahap self evaluation, prototyping dilakukan pencermatan terhadap modul yang telah didesain, penilaian dan evaluasi oleh pakar. Pakar-pakar tersebut menelaah konten, konstruk, dan bahasa dari masing-masing prototipe. Saran-saran para pakar digunakan untuk merevisi modul yang dikembangkan. Kegiatan validasi ini dilakukan untuk mendapatkan masukan terhadap keseluruhan isi materi yang terdapat dalam rancangan modul. Kemudian validasi dilihat pada aspek desain pembelajaran, bertujuan untuk mendapatkan kesesuaian model dan bentuk rancangan dari modul pembelajaran yang dikembangkan. 


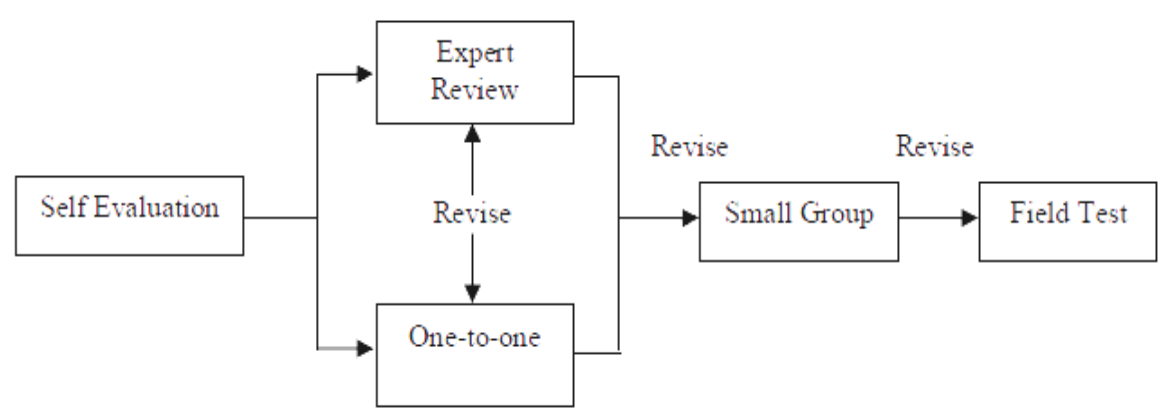

GAMBAR 1. Alur desain formative evaluation (Tessmer, M 1998).

Kevalidan perangkat pembelajaran yang dihasilkan dapat diketahui dengan melakukan validasi modul oleh validator. Hasil validasi dianalisis untuk mengetahui validitas modul baik dari segi isi maupun kostruksinya. Kegiatan validasi dilakukan dua kali. Validasi yang pertama menghasilkan modul yang valid dengan revisi. Setelah dilakukan perbaikan terhadap modul yang pertama, dihasilkan revisi yang kedua pada modul. Hasil pengolahan penilaian lembar validasi kedua dari validator dapat dilihat pada TABEL 1.

TABEL 1. Hasil penilaian validasi kedua modul.

\begin{tabular}{lcl}
\hline \multicolumn{1}{c}{ Validator } & Penilaian & Kesimpulan \\
\hline Validator 1 & 81,06 & Dihasilkan modul pembelajaran yang valid \\
Validator 2 & 82,30 & Dihasilkan modul pembelajaran yang valid \\
\hline
\end{tabular}

Berdasarkan hasil validasi yang didapatkan, maka dapat disimpulkan bahwa modul yang dikembangkan secara keseluruhan sudah sangat valid dengan nilai rata-rata validasi $81,68 \%$. Hasil penilaian validator ini menunjukkan modul telah memenuhi syarat kelayakan isi meliputi kesesuaian dengan kurikulum, struktur keilmuan, aktual, dan keluasan materi. Modul yang dikembangkan menyajikan topik yang sesuai dengan tuntutan kompetensi dasar yang telah dirumuskan. Dengan demikian, modul yang dikembangkan dapat dikatakan valid dan bisa digunakan dalam pembelajaran di kampus. Setelah tahapan validasi modul selesai maka akan dilanjutkan pada tahapan uji coba untuk kelompok kecil (small group).

\section{SIMPULAN}

Berdasarkan hasil penelitian pengembangan modul pembelajaran berbasis guided inquiry pada materi fluida didapatkan rata-rata validasi yang dilakukan oleh pakar adalah 81,68\% yang dikategorikan valid. Validasi modul yang telah dikembangkan dilihat dari validitas isi, validitas konstruk, dan validitas bahasa.

\section{UCAPAN TERIMAKASIH}

Ucapan terima kasih terutamanya disampaikan kepada Kementerian Riset, Teknologi, dan Pendidikan Tinggi Direktorat Jenderal Penguatan Riset Dan Pengembangan atas bantuan dana Penelitian Dosen Pemula tahun 2016 yang diberikan untuk pelaksanaan penelitian ini serta pihakpihak lain yang telah ikut membantu.

\section{REFERENSI}

Mulyasa. 2008. Kurikulum Tingkat Satuan Pendidikan (KTSP). Bandung.

Minner, D.D., Levy, A.J. \& Century, J. 2010. 'Inquiry-based science instruction--what is it and does it matter? Results from a research synthesis years 1984 to 2002'. Journal of Research in Science Teaching", Vol 47. pp. 474-496. 
Plomp, T. An Introduction to Educational Design Research. Enschede: University of Twente. pp 15. Riduwan. 2009. Belajar Mudah Penelitian untuk Dosen, Karyawan dan Peneliti Muda. Bandung. Tessmer, M. 1998. Planning and Conducting Formative Evaluations. Philadelphia: Kogan Page. 